\title{
O projeto gráfico dos livros de bolso como elemento mediador da leitura
}

The graphic project of pocket books as reading mediating element

Sibelle Medeiros, Mestre em Design, PUC-Rio, sibelle.cm@gmail.com;

Jackeline Lima Farbiarz, Doutora em Educação, PUC-Rio, jackeline@puc-rio.br;

Barbara Jane Necyk, Doutora em Design, PUC-Rio, 07barbara@gmail.com.

\section{Resumo}

O presente artigo é parte de uma pesquisa de mestrado em Design cujo recorte de estudo se constituiu em livros de bolso voltados ao gênero da literatura infantojuvenil. Tais publicações são consideradas, como objetos palpáveis capazes de propiciar relações e significados próprios aos seus leitores. Desse modo, buscamos informar sobre os aspectos relacionados às práticas projetuais que acompanham tais publicações, possibilitando um conhecimento maior sobre as maneiras como o design desses livros é apresentado aos jovens leitores e como o design participa da mediação dos processos de fruição da leitura.

Palavras-chave: Design de livros, mediação da leitura, interação

\section{Abstract}

This article is part of a master's degree in Design, the delimitation of the study consisted in pocketbooks aimed at the genre of children's literature. Such publications are considered as tangible objects capable of providing relations and own meanings to your readers. Thus, we seek to inform on aspects related to projective practices accompanying such publications, enabling a better understanding of the ways in which the design of these books is presented to young readers and how design participates in the mediation of reading enjoyment processes.

Keywords: Book design, reading mediation, interaction 


\section{Introdução}

Consideramos necessário para o entendimento de nosso objeto de pesquisa uma breve conceituação dos livros de bolso. Em primeiro lugar, partimos de uma visão que considera que os livros de bolso são caracterizados, principalmente, pelas suas dimensões menores que outras publicações e por seus preços relativamente mais baixos em relação aos demais livros. Partilhamos a definição elaborada por Laurence Hallewell (2005) quando este afirma que as grandes tiragens proporcionam a redução de custos. Desse modo, o livro de bolso é considerado pelo autor como um conceito de marketing atrelado a um projeto editorial e gráfico específico. Tais características possibilitam a elaboração de um projeto gráfico distinto, o qual propicia que o leitor perceba tais publicações como um objeto distinto aos livros publicados em outros formatos. Estas características por sua, vez estabelecem pistas de leitura e exercem influencia nas maneiras como os leitores se relacionam com estes objetos e constroem significados na leitura.

Para o desenvolvimento deste artigo, optamos por realizar uma pesquisa de campo. Esta pesquisa foi realizada 2014 durante visitas ao $16^{\circ}$ Salão da Fundação Nacional do Livro Infantil e Juvenil (FNLIJ), que possibilitou a delimitação do recorte de nosso objeto. A escolha desse cenário para a realização da pesquisa ocorreu em virtude da importância da fundação para legitimação e disseminação da literatura infanto-juvenil. A pesquisa de campo ocorreu em duas etapas distintas. Na primeira etapa, identificamos as editoras que publicavam livros de bolso a partir de sua própria classificação. Sendo assim, encontramos cinco editoras que disponibilizavam livros de bolso aos visitantes do salão. Na segunda etapa, identificamos os gêneros literários disponibilizados em 115 livros de bolso. Com a finalidade delimitar a pesquisa, selecionamos apenas os livros de bolso dedicados ao gênero da literatura infanto-juvenil como objeto análise.

Também optamos por realizar uma pesquisa de caráter bibliográfico. Procuramos estabelecer relações entre o pensamento dos autores com o nosso objeto de estudo, atentando para os aspectos relacionados à prática projetual do design de livros. Para isso, elaboramos algumas categorias de analise vinculadas à materialidade interna dos livros, tais como o formato, tipografia e mancha gráfica. Logo, a análise dos livros de bolso selecionados e de seus elementos constituintes ocorreu através do diálogo com autores como Haslam (2007), Samara (2007), Tschichold (2007), Hendel (2009) e Linden (2011).

\section{Desenvolvimento}

\subsection{0 formato dos livros de bolso}

Consideramos a analise deste elemento como relevante devido ao fato de que a materialidade da obra impressa e seu formato orientam a recepção da obra perante 
os leitores, e, além disso, se relacionam com o modo como uma visão de projeto possivelmente própria aos livros de bolso é apresentada aos jovens leitores. 0 formato físico, baseado nas suas dimensões, é um elemento importante para a definição da totalidade de um texto literário impresso. O formato, assim como outros elementos presentes no design do livro de bolso, orienta atitudes modelo dos leitores, conforme afirma Goulemot (1999). Segundo o autor, existe uma fisiologia que guia o ato da leitura e a maneira como os leitores se relacionam com o texto a partir da relação entre corpo e objeto.

Concordamos com o pensamento de Hendel (2009) quando afirma que a forma física de um livro participa de sua definição e que cada escolha referente à maneira como o livro é apresentado ao leitor causa algum tipo de reação em sua leitura. É a partir do formato que o livro se relaciona com o corpo do leitor e consegue estabelecer uma relação de escala entre estas duas instâncias (leitor e objeto).

Para Haslam (2007), o formato é elemento integrante daquilo que ele considera como a paleta do designer de livros. O autor rompe com a ideia de formato relacionada ao tamanho, afirmando que obras de diferentes tamanhos podem possuir o mesmo formato, como o retrato, a paisagem e o quadrado, por exemplo.

No entanto, nesta pesquisa, optamos por nos aproximar da definição de Linden (2011), que afirma que alguns manuais de diagramação apresentam a diferenciação do formato com base no tamanho do livro em relação à mão do leitor, ou sua fisiologia (GOULEMOT, 1999). Esta diferenciação é organizada em três categorias distintas: a primeira se refere aos livros que são facilmente segurados com apenas uma das mãos quando abertos; a segunda se refere a livros que são segurados com apenas uma das mãos quando fechados e com as duas quando abertos. Finalmente, a terceira é relacionada aos livros maiores, que precisam de duas mãos para segurá-los ou de um suporte para apoiá-los.

Além disso, também consideramos o fato de que a indústria gráfica utiliza frequentemente os termos formato fechado e formato aberto para a elaboração de projetos editoriais. Entendemos que no formato fechado, somente a capa ou quarta-capa é perceptível ao olhar do leitor. Em uma livraria, na maioria das vezes, nosso primeiro contato com um livro ocorre quando este apresenta formato fechado. Já o formato aberto se relaciona à maneira como o livro se apresenta no momento em que ocorre a leitura, onde duas páginas são apresentadas simultaneamente ao leitor.

Os livros de bolso, através de suas características, se encaixam dentro da categoria de pequenos formatos estabelecida por Linden (2011). Além disso, percebemos que no caso dos livros de bolso aqui pesquisados, o formato utilizado é predominantemente o retrato, com altura maior que a largura. No caso de nove livros analisados na pesquisa, também verificamos que a maioria utiliza um formato 
que Haslam (2007) nomeia como derivado dos tamanhos dos papéis disponibilizados no mercado, em virtude da possibilidade de redução de custos que isto representa. Desse modo, percebemos uma ligação com o que Genette (2009) acredita ser a definição tradicional do formato, relacionada às dobraduras de papel necessárias para a construção de um fólio.

Desse modo, com base na definição desenvolvida por Genette (2009), percebemos os livros de bolso como um formato editorial, no sentido de seu conceito mercadológico. Porém, não descartamos a relação existente entre formato e tamanho, entendendo que estas duas instâncias participam da aproximação entre texto e leitor e dialogam com a fisiologia da leitura.

Partilhamos o pensamento desenvolvido por Necyk (2007), de que os livros pequenos apresentam dimensões apropriadas para as mãos da criança e podem passar, com mais facilidade que os livros maiores, uma imagem considerada delicada. Assim, no caso dos livros de bolso pertencentes ao gênero da literatura infanto-juvenil, percebemos que o formato, se bem explorado e em conjunto com os outros elementos constituintes do livro, pode se aproximar de modo efetivo de seus leitores.

\subsection{A tipografia dos livros de bolso}

Consideramos a tipografia como um dos elementos do design do livro que orienta as maneiras como os leitores recebem determinado texto e que participa ativamente dos processos de construção de sentido. É principalmente através desse elemento presente no projeto gráfico de qualquer livro que as palavras dos autores tornam-se visíveis aos seus leitores pela sua fixação em um espaço determinado.

Assim, demonstraremos brevemente como um texto é apresentado a seus leitores a partir das escolhas tipográficas presentes nos livros de bolso de literatura infanto-juvenil selecionados. Convém afirmar que nosso objetivo com esta análise é demonstrar como as escolhas tipográficas exercidas demonstram uma visão de projeto atrelada ao objeto, descartando qualquer pensamento relacionado à validade ou não dessas escolhas.

Neste trabalho, consideramos o fato de que texto torna-se único à medida que seus elementos tipográficos são organizados em uma edição, contribuindo, assim, para diferentes experiências literárias. Hendel (2009) contribui com esse pensamento quando afirma que não é somente o assunto da obra que participa da definição de seu significado e construção de sentido. Para o autor, elementos como o formato e as escolhas tipográficas participam desse processo de definição e constituição de sentido.

Em seguida, o autor afirma que existem três abordagens principais que propiciam a maneira como o design do livro é elaborado através da escolha e organização dos elementos tipográficos. A primeira sugere uma neutralidade, através da adoção de uma tipografia que não remeta a uma época ou lugar 
específico. A segunda se caracteriza por ser alusiva, ou seja, por remeter a uma determinada época ou estilo. Finalmente, a terceira abordagem busca, através da escolha de uma tipografia nova, apresentar o texto de maneira única aos seus leitores.

Nos casos dos livros de bolso aqui analisados, percebemos que majoritariamente, as escolhas tipográficas exercidas na etapa projetual privilegiam uma suposta visão de neutralidade, transparência e impessoalidade do designer, onde o significado deve ocorrer prioritariamente através das palavras do autor e não pelo meio em que estão dispostas aos leitores. Voltamos a ressaltar o fato de que esta neutralidade é somente uma suposição e uma visão de ideal de projeto, pois os dispositivos através dos quais o texto é apresentado ao seu leitor sempre participam ativamente da construção de significados. Consideramos a tipografia um desses dispositivos.

No livro Peter Pan (2011), de autoria de J.M Barrie, publicados pela editora L\&PM, percebemos a adoção de uma família romana de tipos, que não faz nenhum tipo de alusão aos elementos da narrativa ou à época em que a obra foi escrita. Além disso, a tipografia não é utilizada para dar ênfase aos personagens ou suas falas e não auxilia no estabelecimento de ritmo na obra, o que, segundo Ellen Lupton (2006), poderia ser estabelecido através de quebras, contrastes e variações de tamanho e posicionamento ao longo da página. De modo geral, todos os livros da mesma editora analisados nessa pesquisa seguem a mesma lógica de escolhas tipográficas.

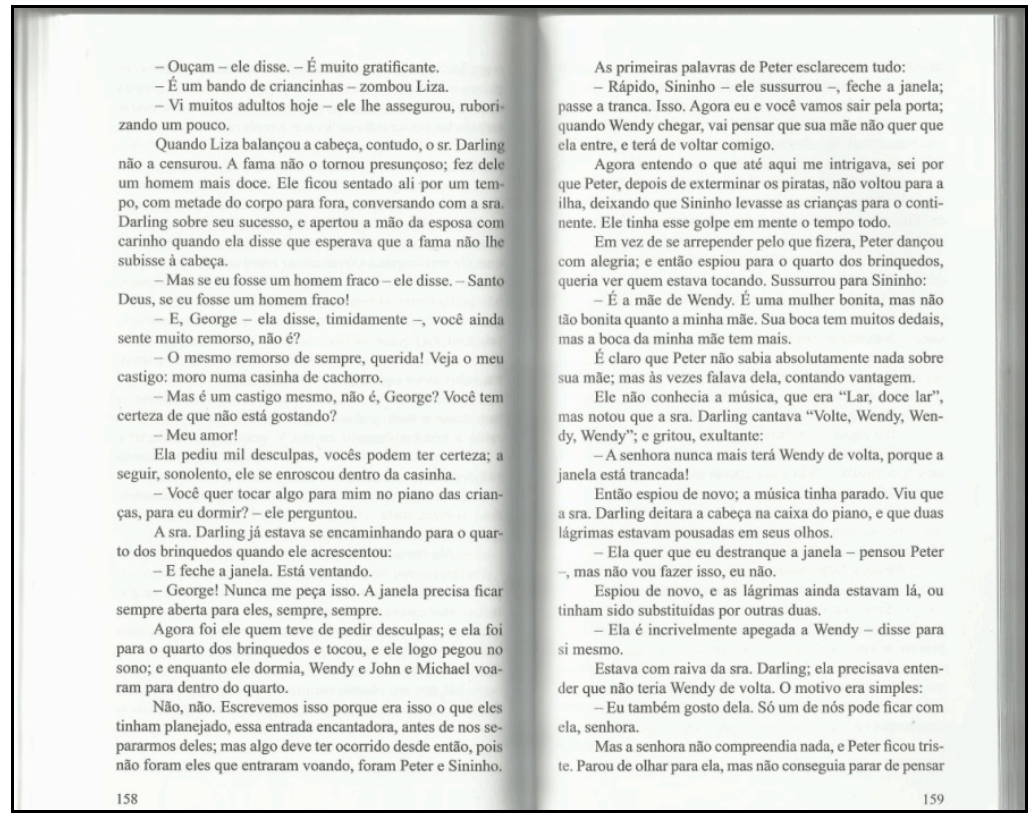

Figura 1: Páginas internas do livro Peter Pan (2011), publicados pela editora L\&PM. 
Em Uma Casa na Floresta (2012), de Laura Ingalls Wilder, publicado pela BestBolso, notamos que é mantida uma visão logocentrista da tipografia. Apesar de utilizar o recurso de Versal Versalete, não se percebe, por exemplo, as variações que valorizam uma apreensão do significado da obra através da visualidade tipográfica nem a adoção de elementos voltados ao universo infantil, como a caligrafia, por exemplo.

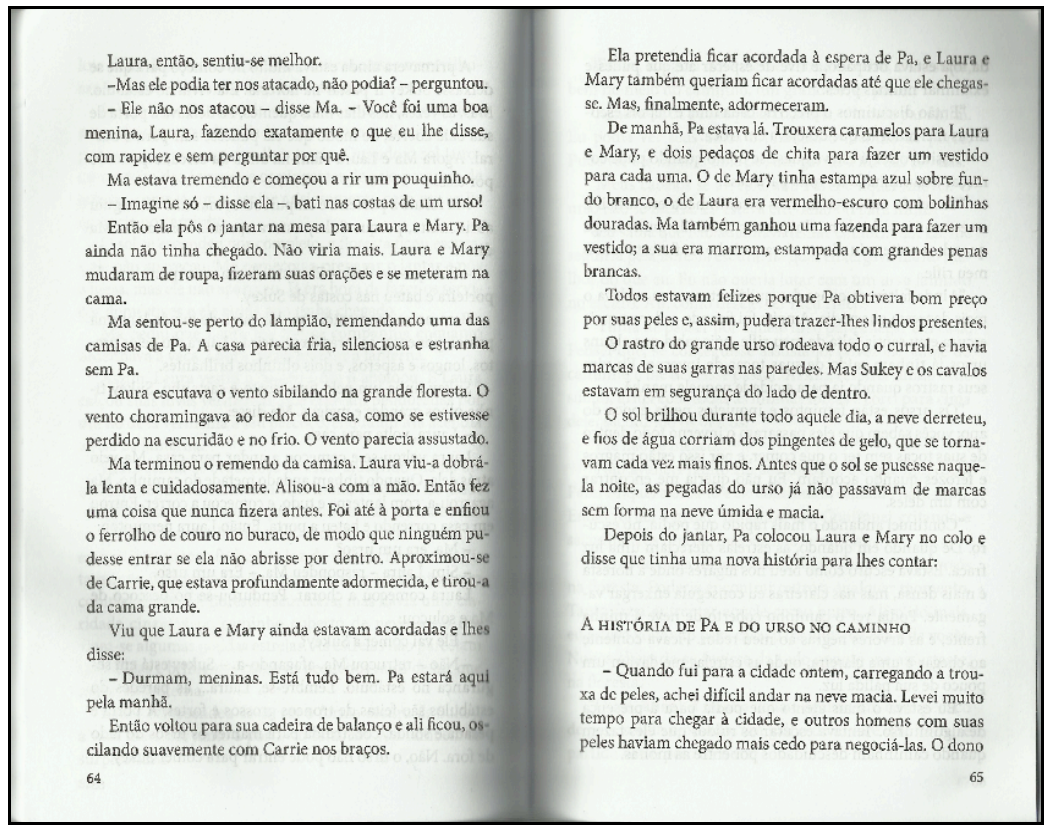

Figura 2: Páginas internas de Uma Casa na Floresta (2012), publicado pela BestBolso

Voltamos a afirmar que qualquer tipografia orienta o leitor na construção de sentidos, seja ela considerada neutra ou não, porém, nestes projetos gráficos de livros de bolso de literatura infanto-juvenil, as escolhas exercidas não demonstram intencionalidade de intervenção direta na fruição da leitura. A problemática torna-se ainda maior se considerarmos o público infantil e suas especificidades, pois questiona-se em que medida a manutenção de uma visão logocentrista nos projetos de livros de bolso potencializa ou não o design como agente mediador da experiência de leitura e da formação de novos leitores. Ao retomarmos os conceitos de legibilidade e leiturabilidade expostos anteriormente, podemos concluir que todos os livros analisados possuem legibilidade, pois as fontes tipográficas não possuem características que impossibilitem a leitura da obra. No entanto, a análise desses livros nos permitiu ver que não é estabelecida nenhuma relação tipográfica ou recurso visual que dialogue com o repertório infantil e enriqueça o conteúdo narrativo da obra. Desse modo, podemos perceber que a leiturabilidade dos livros de bolso do gênero infanto-juvenil poderia ser melhor explorada nos projetos gráficos através da revisão do papel ocupado pela tipografia no conteúdo narrativo e visual. 


\subsection{Mancha gráfica e grid}

Se através da tipografia as palavras do autor tornam-se legíveis aos seus leitores, é por meio da mancha gráfica e do grid que o conjunto dessas palavras é apresentado a eles. Ambos os elementos e sua relação com aquilo que não está impresso são fundamentais para a elaboração de uma unidade interna para qualquer tipo de publicação. $O$ diálogo existente entre o espaço ativo de uma página e seu negativo, aquilo que não está impresso, participa ativamente da produção de sentido de uma obra e auxilia na compreensão de uma visão de projeto que envolve os livros de bolso enquanto objeto.

Ambrose e Harris (2009) definem o grid como elemento que estabelece ordem e estrutura em uma composição visual. Para os autores, o grid tem como função principal a organização de informação em uma página e fornece estruturas que ajudam a criar referências que guiam o posicionamento dos elementos em uma página.

De acordo com Samara (2007), o grid consiste em um conjunto de relações de alinhamentos que trabalham como guias e auxiliam a distribuição de elementos em um determinado formato de página. Além disso, o autor afirma que o grid proporciona uma ordem sistemática em layout, diferenciando as informações fornecidas e facilitando a navegação no projeto gráfico. Desse modo, podemos dizer que o grid auxilia os designers na etapa de elaboração do projeto e os leitores, que conseguem, através da organização visual, diferenciar os conteúdos fornecidos em determinado trabalho.

Na maioria dos livros dedicados ao gênero romance ou em textos longos que não apresentam diferentes níveis de informação, percebemos predominantemente a adoção de um grid retangular em seu projeto. Samara (ibidem) afirma que esta estrutura é considerada mais simplificada e que possui duas estruturas. A primária é composta pelo bloco de texto e pelas margens que definem a posição desse bloco dentro da página. Já a secundária participa da definição de outros detalhes considerados importantes, como o número da página e o título corrente, se previsto no projeto.

Samara (2007) também alerta sobre a importância de manter o interesse visual na adoção do grid retangular. A proporção das margens e seu ajuste são, para ele, uma das principais maneiras de manter este interesse e de gerar conforto para a leitura de textos longos. De acordo com o autor, margens maiores auxiliam na permanência do foco visual, enquanto as margens estreitas aumentam a tensão dos leitores devido ao fato de que a mancha gráfica se apresenta muito próxima ao limite do formato, nesse caso, do livro de bolso.

As proporções das margens das páginas de um grid retangular podem ser construídas a partir de vários parâmetros baseados em cálculos matemáticos. Parece-nos visível que os livros de bolso analisados nessa pesquisa optam por utilizar um grid simétrico com a adoção de margens na mesma proporção do 
formato. Haslam (2007) afirma que essa é uma das maneiras mais simplificadas de se obter o tamanho das margens nas páginas de um livro. Para a criação de páginas que se utilizam dessa proporção, o autor afirma que basta a marcação de duas diagonais que atravessam ambas as páginas; após esta marcação, desenha-se um novo retângulo, de modo que faça a intersecção com as diagonais marcadas anteriormente. $\mathrm{O}$ autor também afirma que o bloco oriundo dessas marcações pode sofrer alterações de posicionamento que visam aproximá-lo à parte superior da página. Com isso, são obtidas margens com tamanhos distintos, mas que possuem a mesma proporção do formato da página.

Explicitamos abaixo de maneira visual como é estabelecida a proporção das margens e da mancha gráfica a partir do formato do livro:
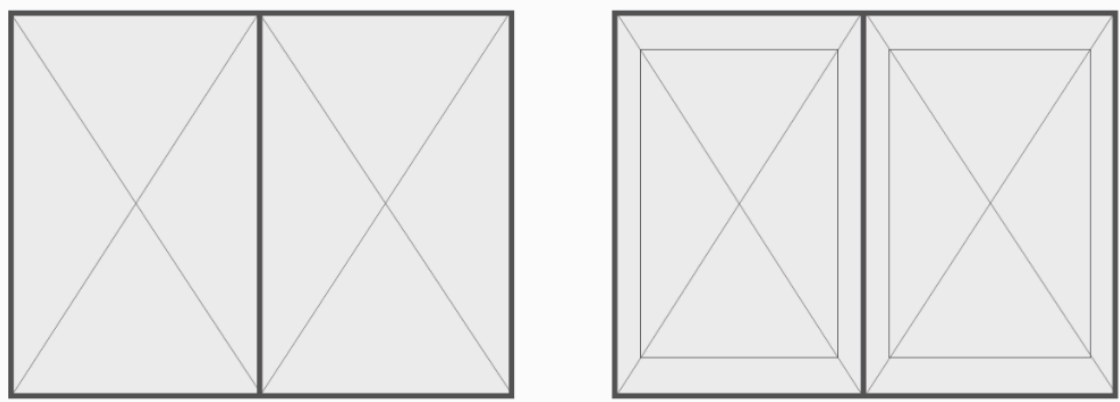

Figura 3 - Margens e mancha gráfica adquiridas a partir da proporção do formato

Gostaríamos de apontar que o tamanho da mancha gráfica e das margens também participa da definição dos livros de bolso e nos auxilia na compreensão da visão de projeto que os acompanha. Encontramos relevância na classificação dos grids retangulares, realizada por Collaro (2010). O autor afirma que é possível diferenciar edições de luxo, normais e econômicas a partir da proporção do conteúdo impresso em uma página. Para ele, uma página ligada a uma edição de luxo deve apresentar $25 \%$ de espaço dedicado à mancha gráfica, enquanto os $75 \%$ restantes devem estar ocupados pelas margens. Para ser considerada normal, a edição deve apresentar $50 \%$ de conteúdo impresso e $50 \%$ de margens. Finalmente, para ser considerada econômica, a edição deve ter mais de $75 \%$ dos espaços de sua página dedicados aos conteúdos impressos do livro.

Nos livros de bolso pesquisados, encontramos a confirmação do que os autores citados anteriormente comentam sobre o grid e a mancha gráfica. No livro Pinóquio (2014), publicado pela editora L\&PM e pertencente à coleção $L \& P m$ Pocket, encontramos a aplicação de um grid retangular e simétrico em suas páginas. Aparentemente, o cálculo das margens foi adquirido com base nas proporções do formato e o tamanho da mancha gráfica, de $8,3 \times 16 \mathrm{~cm}$, corresponde ao que Collaro (2010) define como econômico. 


\section{V SILID IV SIMAR}

PUC-Rio - Dias 28, 29 e 30 de julho de 2015

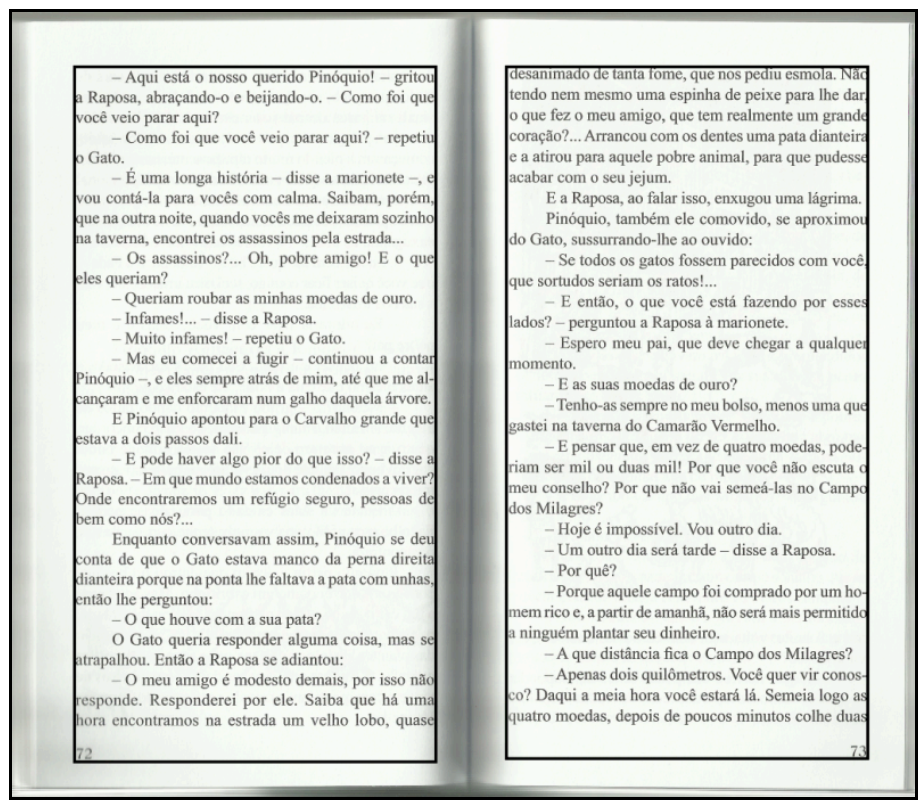

Figura 4: Página interna do livro Pinóquio (2014) com aplicação de grid assimétrico.

Situação semelhante foi encontrada no livro Contos de Fada (2010), publicado pela editora Zahar na Coleção Bolso de Luxo. Aqui também se encontra a aplicação de um grid retangular simétrico com suas margens calculadas com base na proporção do formato do livro. Embora a coleção se denomine de luxo, com relação à mancha gráfica, percebemos que é considerada econômica, pois possui ocupação maior do que $75 \%$ do total da página, com dimensões de $9 \times 15 \mathrm{~cm}$.

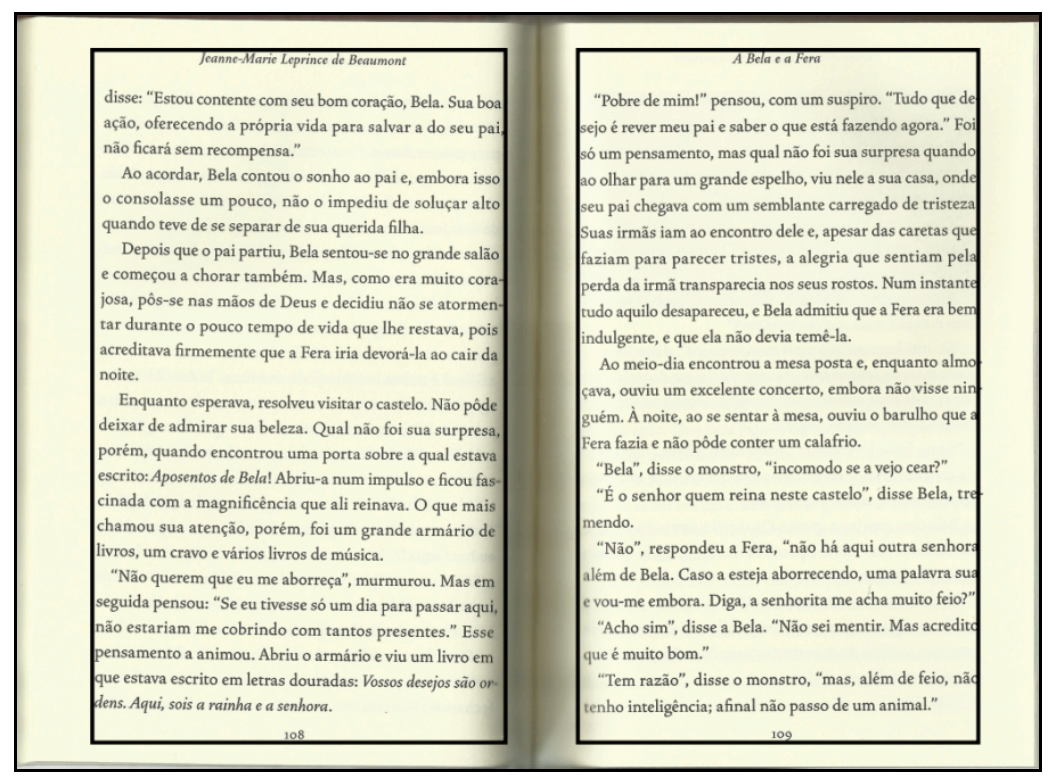

Figura 5: Página interna do livro Contos de Fada (2014) com ampla mancha gráfica 
A análise da maneira como o grid dos livros de bolso é estruturado e como a mancha gráfica é disposta nas páginas internas de duas publicações distintas e pertencentes cada a uma coleção diferente, nos leva a perceber que em um primeiro momento que os agentes produtores optam pela manutenção de determinados fatores em detrimento de pequenas mudanças estruturais que poderiam ser significativas na reaproximação dos jovens leitores a estas obras. Percebemos que todos os livros possuírem um grid composto por uma única coluna e serem simétricos. Além disso, adoção de uma mancha gráfica que por vezes quase ocupa todos os espaços da página, nos leva a perceber que muitas vezes a questão de barateamento de custos se revela mais importante para os agentes produtores do que a questão da fruição da leitura. Finalmente, voltamos a afirmar que compreendemos que os livros de bolso, possuem características próprias que estão engendradas ao seu formato editorial e que as diferenciam dos demais tipos de publicação, a adoção de uma mancha gráfica ampla e de um grid predominantemente simétrico nos parecem ser algumas dessas características.

\section{Conclusão}

Conforme explicitado acima consideramos o designer como agente produtivo nos processos de mediação da leitura. Ao fazer uso de expectativas pré-existentes o design orienta a visão dos leitores sobre um determinado objeto, seja antecipando ou se estabelecendo a manutenção das experiências obtidas na relação entre leitor e livro. Não acreditamos na existência de um design neutro, invisível e passivo frente aos aspectos textuais de uma obra. A análise realizada neste artigo nos possibilitou perceber que as editoras que publicam livros de bolso do gênero da literatura infanto-juvenil, optam na maioria das vezes pelo estabelecimento da manutenção desses ideais projetuais nas partes em que a textualidade é apresentada com maior densidade, como nas páginas internas, por exemplo.

Porém, mesmo que estes ideais de neutralidade sejam considerados no ato de projetar, intuímos que no ato da leitura não existe passividade exercida pelo design. A maneira como um texto é apresentado aos seus leitores através de seus dispositivos visuais, como a tipografia, sempre orienta os processos de construção de sentidos, através do dialogo adquirido com as experiências anteriores dos leitores e sua visão de mundo. Além disso, o próprio design se configura como fenômeno da linguagem e da comunicação e conforme explicitado no capítulo 6, às escolhas projetuais vinculadas aos livros de bolso seu como formato, sua tipografia, sua mancha gráfica participam dos processos de definição desse objeto enquanto gênero do discurso.

Assim, consideramos o fato de que para ser reconhecida como tal pelos leitores, a manutenção de determinados parâmetros projetuais seja determinante nos processos de diferenciação dos livros de bolso das demais publicações existentes no mercado editorial. No entanto, também nos atentamos no fato de que 
somente a manutenção desses parâmetros, estabelecidos há décadas, sem abrir lugar para a inovação pode afastar os jovens leitores cada vez mais inseridos em um contexto social marcado pela mudança e efemeridade.

\section{Referências Bibliográficas}

AMBROSE, Gavin; HARRIS, Paul. Design básico: grids. Porto Alegre: Bookman, 2009

BARRIE, J.M. Peter Pan. Porto Alegre: L\&PM, 2011

COLLARO, Antônio Celso. Projeto Gráfico - teoria e prática da diagramação. São Paulo: Summus, 2000.

COLLODI, Carlo. Pinóquio. Porto Alegre: L\&PM, 2014.

GENETTE, Paratextos Editoriais. Cotia: Ateliê Editorial, 2009.

GOULEMOT, Jean Marie. Da leitura como produção de sentidos. In: CHARTIER, Roger (dir). Práticas de leitura. São Paulo: Estação Liberdade, 1999. HALLEWELL, Laurence. O livro no Brasil. São Paulo: Edusp, 2005.

HALLEWELL, Laurence. O livro no Brasil. São Paulo: Edusp, 2005.

HASLAM, Andrew. O livro e o designer II - Como criar e produzir livros. São Paulo: Edições Rosari, 2007

HENDEL, Richard. O Design do livro. Cotia: Atelie Editorial, 2003.

LINDEN, Sophie Van der. Para ler o livro ilustrado. São Paulo: Cosac Naify, 2011. LUPTON, Ellen. Pensar com tipos. São Paulo: Cosac Naify, 2006.

NECYK, Barbara Jane; CIPINIUK, Alberto. Texto e imagem: um olhar sobre o livro infantil contemporâneo. Rio de Janeiro, 2007. Dissertação (mestrado em Design)- Pontifícia Universidade Católica do Rio de Janeiro

PERRAULT; GRIMM; ANDERSEN \& outros. Contos de Fadas. Rio de Janeiro: Zahar, 2010.

SAMARA, Timothy. Grid: Construção e desconstrução. São Paulo: Cosac Naify, 2007 
TSCHICHOLD, Jan. A forma do livro: ensaios sobre tipografia e estética do livro. Cotia: Ateliê Editorial, 2007.

WILDER, Laura Ingalls. Uma casa na floresta. Rio de Janeiro: BestBolso, 2012. 